\section{Dear Mary}

\author{
by Mary Annas
}

Dear Mary is a monthly feature in which readers' can ask about any nursing care issue that concerns them. Answers will be supplied by Mary Annas or a consulting nurse, physician, lawyer, or ethicist where appropriate. Readers are also invited to comment on the answers. Letters to Dear Mary may be handwritten. All inquiries should be addressed to Mary Annas, Nursing Law \& Ethics, P.O. Box 9026, JFK Station, Boston, MA 02114 .

\section{Dear Mary,}

As a delivery room nurse I have two questions for you. First, what is the legal reason for using silver nitrate on the eyes of newborns? Second, since it is my understanding that silver nitrate is applied to prevent the potential transmittal of gonorrhea from the mother as the baby passes through the birth canal, why should babies born by cesarean have to have silver nitrate drops?

Lake Tahoe, California

\section{Dear Diane,}

Since the question you pose is a legal one, I have referred it to Barbara $F$. Katz, J.D., a member of our Editorial Advisory Board and of the Task Force on Cesarean Childbirth of the National Institutes of Health.

Most states have laws which require the administration of silver nitrate or a similar prophylactic into the eyes of newborns. Generally, these laws place the duty to perform on the physician or other birth attendant, and make it a minor criminal offense to fail to do so. While these statutes do not specifically require the consent of the parents prior to administration, a number of them do provide that it will not be done if the parents object on religious grounds.

None of the statutes make any distinction regarding method of delivery. Thus, the silver nitrate is required whether the baby is born by vaginal delivery or cesarean birth. This is so even though when a baby is born by planned cesarean birth, and the membranes are intact, there is medically little or no risk of infection to the infant's eyes, and accordingly no medical reason for administration of the prophylactic.
In some states hospitals give the parents a choice as to the method of prophylaxis that will be used - silver nitrate drops or tetracycline ointment.

Barbara F. Katz, J.D. Associate Counse University of Massachusetts

Dear Mary,

As a student on maternity rotation I would like your opinion of a situation encountered by a patient to whom I was assigned.

The patient had received her prenatal care at an $\mathrm{OB}$ clinic. Having had an epidural for her first delivery, she decided to do so again, and the physician whom she saw regularly concurred. However, another physician was on call when my patient went into labor, but this doctor kept delaying administration of anesthesia, and the child was finally born without the mother having been medicated. The patient had a fairly difficult labor and was quite distressed.

Discussing the incident later with one of the regular floor nurses, I heard that this is common practice for that particular physician. She's an aggressive proponent of natural childbirth and reportedly had done this before. This seems to me to be very unethical behavior on the physician's part. What do you think?

\section{Mary}

Key West

Dear Mary,

The obvious problem with $O B$ clinics, or with any group practice, is that the patient often gives birth at a time when the caregiver with whom she has built a relationship is not covering It is highly unethical of any health care provider to impose her personal preferences on a patient, especially in a situation like labor and delivery when the patient is so vulnerable.

Many people who teach childbirth classes think that the patient should have a statement, signed by her obstetrician or a representative of the clinic she attends, regarding her wishes about treatment during delivery. While such an agreement may not be legally binding, a previously written document brings the matter to the consciousness of all attending the birth, making the mother's preferences more difficult to dismiss. Of course, if difficulties arise it is expected that the patient will be flexible about changing her wishes, should it be necessary for her own or the baby's safety.

The existence of such a document also makes it easier for a nurse in attendance to act as an advocate for the patient, and either question the doctor directly, probably in private, or notify the head nurse or other appropriate party that there appears to be conflict between the patient's desires and the physician's practice.

\section{Dear Mary,}

I know this is an old complaint, but has anyone come up with a better idea for hospital gowns than standard-issue johnnies? I work on a geriatric floor and many of the women patients especially are distressed by the lack of per. sonal privacy these garments afford. It doesn't bother patients who wear their own nightclothing, but those who don't want to or can't afford to wear their own clothes could use a gown that's less revealing and maybe even more flattering. It's hard enough to be elderly and hospitalized without having one's modesty stripped away too. Do you have any suggestions?

\section{Woodruff, Wisconsin}

\section{Dear Barbara,}

The lack of dignity allowed patients by their hospital johnnies has been a problem for a long time. Of course, hospital personnel should be mindful that patients have a right to wear their own clothing or nightclothing, as long as it doesn't interfere with their care. But patients who can't or don't choose to wear their own garments have to deal with one more dehumanizing aspect of hospitalization.

An article in the New York' Times (January 18, 1981) described "a designer version of the traditional hospital johnny." Humana Inc. of Louisville, Kentucky is marketing a gown with a deep pleat, held by snaps at the neckline, that's supposed to eliminate the problem of exposure. It has shirt-tails, is made of cotton/polyester blend, and sells for about $\$ 4.25$. Never having seen them, I can't comment firsthand on their quality or attractiveness, but you can get more information from the Opelika Manufacturing Company, 361 West Chestnut Street, Chicago, Illinois 60610 .

\section{Dear Mary,}

I have enjoyed reading Nursing Law $\&$ Ethics and feel many of the nursing care issues are applicable to my situation as Director of Nursing in a 160 bed acute care hospital. I have a problem I would like to ask your advice in solving.

One of the surgeons on our staff drew up a form for postoperative orders, to be used by the recovery room nurse. She is expected to discuss each patient with the surgeon, then place the (Continued on page 13) 
Exit House stood firmly in my mind. It stood solidly and brilliant with new light upon it, dynamically detailed by years of my mind's exploration . . .

Roman devoted herself to creating her own Exit House, carefully selecting the family and friends who would assist her. It was most important to her to select an exit date which would not be premature, but which would allow her to end her life while she still felt well, to give up her body "before it wrecks us all." For this she needed medical cooperation - a "best guess" as to her prognosis. She "lost" ten months undergoing fruitless chemotherapy before finding a sympathetic physician.

I could see the doctor's struggle in his eyes. He had enough respect for me and self-confidence not to avert his look. Could I really count on him to level with me? This stranger? This man... with years of indoctrination to extend life at all cost and to deny suicide? . . I could feel hope not only because he permitted the [suicide] dialogue (of course, the control was his), but because, to my amazement, he had dared to give me information other doctors must have known and withheld . . . I felt hope for forthright communication with someone who had the medical information I needed in order to make the best plan for my life. My probably shortened life.

Part of the book is devoted to Roman's description of her life, particularly as it influenced her views on life and death. She reveals a preoccupation with suicide and a serious suicide attempt made after, as a young widow, she gave up her two children for adoption. This revelation will allow some readers to label the author a "flake" or otherwise discredit her philosophy. But, of course, Roman has the ultimate credibility. She created her own Exit House involving people she trusted, and ended her life in "loving accompaniment."
While not all, and perhaps very few, health professionals will agree with Jo Roman's ideas, EXIT HOUSE is a worthwhile read because it stimulates examination of one's own views on individual autonomy and quality of life. Roman says it well:

We and our doctors have become strangers to one another, as separated from the human factor as are the high-altitude bomber and his target. In the doctors' favor we can say at least that they mean well. Does the bomber tell himself the same? I am not suggesting it is the doctor's responsibility to solve our dilemma, any more than I think it is the bomber's responsibility that we have war. Neither war nor wanton extension of life without regard for quality can be resolved by anyone except ourselves.

Jane L. Greenlaw

\section{Dear Mary Continued}

orders on the chart with the following notation: "As per standing orders of John Smith, M.D., per Mary Jones, R.N." The chart then goes to the unit with the patient, and the nurse on the unit is responsible for signing off the orders and seeing that Dr. Smith signs them within 24 hours.

My staff and I are very concerned about the legality of using such orders. The ones developed for our use allow many occasions for error. Certain orders must be crossed out if they do not apply; some apply to immediate recov. ery room care, and some apply to postoperative care nine days later. If any of these orders are changed, new orders are to be written on the final sheet. All of these factors make mistakes possible.

I feel these orders are putting my staff into legal jeopardy, and would like your comment as to whether you feel these typed orders are acceptable in a patient's chart.

\section{Jean}

Milledgeville, Georgia

\section{Dear Jean,}

Since your question is primarily a legal one, I have referred it to Loretta M. Costa, a member of our Editorial Advisory Board, who is a nurseattorney in private practice.
The following is an answer to your letter and does not constitute legal advice. For a legal opinion you should contact local counsel.

Standing orders have long been used by nurses but their use does raise issues concerning liability. Standing orders are based on the concept that there are standard methods of treatment for particular diseases and medical problems, but the use of such orders places a greater responsibility for judgment about individualized patient care on the nurse. This can be a double-edged sword. In making judgments nurses are sometimes called upon to diagnose, an area generally defined as the practice of medicine. An example of this greater responsibility is the classic $C C U$ standing order where the nurse is to defibrillate if the patient is having ventricular fibrillation. Obviously, the nurse must make a diagnosis to carry out this order. Use of standing orders and regular routines for patient care can be appropriate. However, safety should not be sacrificed for expediency's sake.

I would suggest that standing orders be grouped according to time period, so that all orders pertaining to the first twenty-four hours are presented first, then the first day post-op, the second day, etc. Regarding the sign-off noting process, I recommend that the recovery room nurse who discusses the orders with the physician also be the nurse who notes the orders. I would also have the physician sign the orders in the recovery room.

Standing orders should be very clear and specific. If the orders refer to treatment routines, those routines should be spelled out in detail in the hospital procedure book or manual. If there are several possible categories within a given treatment, each should be plainly listed so that the appropriate ones can be checked off. However, if the routines referred to in the orders are ones "everybody knows," then the orders should be more specific or the routine should be formalized in another document. This is especially necessary if your hospital uses "non-employee" or registry personnel.

The most important thing in decreasing the risk of legal liability in using standing orders is that the nurses understand that judgment is to be used in the implementation of the orders and if any questions arise concerning the implementation of an order versus the well being of a patient, the order should be questioned and discussed with the physician.

Loretta M. Costa

Attorney at Law 126 Post Street San Francisco, California 